\title{
Dendritic Arbors of Large-Field Ganglion Cells Show Scaled Growth during Expansion of the Goldfish Retina: A Study of Morphometric and Electrotonic Properties
}

\author{
Stewart A. Bloomfield ${ }^{1}$ and Peter F. Hitchcock ${ }^{2}$ \\ 'Department of Ophthalmology, New York University Medical Center, New York, New York 10016 and ${ }^{2}$ Department of \\ Ophthalmology and Department of Anatomy and Cell Biology, W. K. Kellogg Eye Center, University of Michigan, Ann \\ Arbor, Michigan 48105
}

The retina of the goldfish grows by a balloon-like expansion and by the addition of new neurons at the margin. It has been proposed that as a consequence of this expansion the dendritic arbors of ganglion cells in central retina grow in a uniform manner without the addition of new branches. In the present study, we have examined this proposal by comparing the geometries of individual dendritic arbors of largefield ganglion cells from the retinas of small/young and large/ old fish. These comparisons were based on measurements of several parameters of dendritic morphology, including number of segments and branches, branch angles, changes in diameter at branch points, and proximal versus distal distribution of arbor length. In addition, we used passive, steady-state cable modeling as an independent method of estimating the functional architectures of small and large dendritic arbors. Our morphometric data indicate that, though they are very different in absolute size, dendritic arbors of small and large ganglion cells have remarkably similar architectures. Analysis with steady-state cable equations indicates that the arbors from small and large cells have equivalent electrotonic lengths and show comparable propagation of synaptic currents. These data are consistent with the hypothesis that dendritic arbors of small and large ganglion cells are scaled versions of one another. We conclude that the growth of these cells during the expansion of the retina is the result of the addition of dendritic mass to an arbor whose basic geometry remains unchanged.

Brain growth results from both neuronal hyperplasia and hypertrophy. The latter is generally protracted compared to the period of neurogenesis and reflects a net increase in cellular mass and, perhaps, complexity via the continued addition of new elements at the molecular level. During brain hypertrophy, the integrative properties of neurons must be preserved, however,

\footnotetext{
Received July 9, 1990; revised Oct. 12, 1990; accepted Nov. 13, 1990.

This work was supported by NIH Grants EY07360 and BRSG S07 RR05399. 28 awarded to S.A.B., by NIH Grant EY01842 (CORE) and an unrestricted grant from Research to Prevent Blindness, Inc., awarded to the Department of Ophthalmology, NYU Medical Center, and by NIH Grants EY07060 and EY07003 (CORE) and NSF Grant BNS 8607886 awarded to P.F.H. S.A.B. is the grateful recipient of a Research to Prevent Blindness Manpower Award. We thank Dr. Stephen Easter for providing comments on the manuscript.

Correspondence should be addressed to Dr. Stewart A. Bloomfield, Department of Ophthalmology, New York University Medical Center, 550 First Avenue, New York, NY 10016.

Copyright (C) 1991 Society for Neuroscience $0270-6474 / 91 / 110910-08 \$ 03.00 / 0$
}

to ensure continued, normal processing of sensory information and, in immature animals, the emergence of normal behaviors.

The retina of the goldfish is a useful tissue for studying brain hypertrophy because it grows throughout the life of the animal primarily by a balloon-like expansion (Easter et al., 1977; Johns and Easter, 1977; Kock and Reuter, 1978a; Kock, 1982a). This retinal hypertrophy results in an increase in retinal area, a decrease in neuronal planimetric density, and an increase in the size and area of ganglion cell dendritic arbors (Kock and Reuter, 1978b; Kock, 1982b; Hitchcock and Easter, 1986). In addition, there is a concomitant synaptogenesis within the inner plexiform layer (Fisher and Easter, 1979).

In the present study, we have examined the hypertrophy of the dendritic arbors of ganglion cells in the continually growing retina of the goldfish in order to test the proposal that these arbors grow interstitially and uniformly (Hitchcock and Easter, 1986) and to gain some insights into the functional consequences of this type of dendritic growth. Although we are unable to examine directly the same dendritic arbor at younger and older stages of development, we have taken advantage of the finding of Hitchcock and Easter (1986) that, by examining a morphological subtype of ganglion cell in restricted regions of the retinas from small/young and large/old fish, one can effectively "see" a cell at early and late stages of growth. We compared the arbors of a well-described morphological subtype of ganglion cell (type 1.2; see Hitchcock and Easter, 1986) in the small retinas of young fish and the large retinas of older fish. Two avenues of investigation were taken: First, morphometric parameters of single dendritic arbors of these ganglions cells were examined to determine quantitatively the similarity in their branching patterns. Second, passive, steady-state synaptic current flow within these same arbors was modeled. Because we would expect arbors that are scaled versions of one another to display similar passive, electrotonic properties, this electrical modeling provided an independent evaluation of the arbors' dendritic geometry. Together, our anatomical and electrical data support the proposal that the dendritic arbors of ganglion cells enlarge in a simple balloon-like manner, with no change in their basic architecture.

Portions of these data have been presented in preliminary form elsewhere (Bloomfield and Hitchcock, 1989).

\section{Materials and Methods}

Histology. The histological procedures used here have been described previously in detail (Hitchcock and Easter, 1986). Briefly, fish were 
anesthetized by immersion in $0.1 \%$ tricaine methanesulfonate (MS 222). The orbit was opened dorsally to expose the optic nerve, which was then sectioned partially, and a pledget of Gelfoam soaked in $20-30 \%$ horseradish peroxidase (HRP) dissolved in $2 \%$ dimethyl sulfoxide was placed on the nerve. After 2-4 d survival, retinas were isolated and fixed either in $2 \%$ glutaraldehyde in $0.1 \mathrm{~m}$ phosphate buffer $(\mathrm{pH}, 7.4)$ for 30 minutes or in a mixture of $2.5 \%$ glutaraldehyde $/ 2.0 \%$ paraformaldehyde in $0.08 \mathrm{~m}$ Sorensen's phosphate buffer $(\mathrm{pH}, 7.4)$ for $1 \mathrm{hr}$. HRP was visualized using 3,3'-diaminobenzidine (DAB) as the chromagen (Adams, 1977). Following the HRP reaction, retinas were wholemounted on gelatinized slides, dehydrated in alcohols, cleared in xylenes, and coverslipped.

Partial sectioning of the optic nerve usually results in HRP labeling of many ganglion cells in a restricted region centered upon the optic disk and numerous, scattered cells that are relatively isolated from the other labeled ones. Data were collected only from these well-isolated neurons. Single dendritic arbors from 6 HRP-labeled, large-field (type 1.2) ganglion cells were digitized using a light microscope (Zeiss) equipped with a $100 \times$ oil-immersion lens, coupled to a computerized reconstruction system (Eutectic). Cells were entered into the computer using $x-$, $y-$, and $z$-coordinates so that 2-D length information and depth information were combined to create a 3-D reconstruction. The diameters of dendritic segments were entered into the computer using a computergenerated circular target whose size could be adjusted to match the thickness of the dendrite. The computer program provided a drawing and detailed morphometric information for each arbor. We assigned the branch points between the primary dendrite and its daughter dendrites a branch order of 2 , the next most distal branch points a branch order of 3, and so on (see Fig. 3). Dendritic segments (a piece of dendrite between 2 branch points) were assigned branch orders in a similar fashion, with the segments between the soma and the first branch point assigned a branch order of 1 (see Fig. 5).

Modeling of electrical properties. Attenuation of synaptic potentials within the individual arbors was modeled using passive, steady-state cable theory described by Rall (1959). Briefly, dendritic segments within a single arbor were considered electrically passive cables with constant specific membrane $\left(R_{m}=5000 \Omega-\mathrm{cm}^{2}\right)$ and specific internal $\left(R_{i}=100\right.$ $\Omega$-cm) resistances. The length constant $(\lambda)$ of individual dendritic segments was calculated using the formula

$$
\lambda=\left(\frac{K_{m}}{R_{i}} \frac{d}{4}\right)^{1 / 2},
$$

where $d$ is the diameter of the segment. The electrotonic length $(L)$ of the segment was computed from the equation

$$
L=l / \lambda \text {, }
$$

where $l$ is the length of the segment. The electrotonic distance of a point of voltage application (i.e., a synapse) from the soma was calculated by adding the electrotonic lengths of all individual dendritic segments forming the pathway from the injection site to the soma.

In order to estimate the voltage attenuation within a branching dendritic tree, it was first necessary to calculate the input conductance of each dendritic segment. The input conductance of the $k$ th branch can be expressed as

$$
G_{k}=B_{k}(\pi / 2)\left(R_{m} R_{i}\right)^{-1 / 2}\left(d_{k}\right)^{3 / 2},
$$

where $B_{k}$ is a factor that relates the input conductance of the dendritic branch to a reference value provided by an infinite extension of the branch. $B_{k}$ was calculated by the equation

$$
B_{k}=\frac{B_{k+1}+\tanh \left(l_{k} / \lambda_{k}\right)}{l_{k}+\left(B_{k+1}\right) \tanh \left(l_{k} / \lambda_{k}\right)}
$$

where $l$ is the length of the $k$ th dendritic segment and $B_{k+1}$ is the conductance factor that depends on the branches arising from the next higher-order branch point. At each branch point, $2 B_{k}$ factors were generated, 1 for each daughter dendrite, and

$$
B_{1}=\sum B_{k}\left(D_{d} / D_{m}\right)^{3 / 2},
$$

where $D_{d}$ is the diameter of the daughter branch and $D_{m}$ is the diameter of the mother branch.

To calculate the $B$ factors for an entire dendritic arbor, values were computed for individual branches, beginning at the most distal and proceeding sequentially toward the soma. We assumed that $B_{k}$ for terminal branches was 0 ; this approximates a dendrite whose ending is sealed with a relatively high resistance. The $B_{1}$ for the corresponding branch point was thus calculated to be 0 , and this was used as the $B_{k+1}$ value for the next most proximal branch. The sequential computation of $B$ factors for more proximal dendritic segments led to the $B_{0}$ value used to calculate the input conductance of the dendrite at the soma origin.

The steady-state voltage attenuation along a dendrite is constrained by the boundary conditions (e.g., sealed vs. open endings) "seen" by current flow within the segment. The $B$ factors calculated for each branch point vary depending upon these boundary conditions. The general solution for voltage attenuation along a dendrite is

$$
V / V_{1}=\cosh (l / \lambda)+B_{1} \sinh (l / \lambda),
$$

where $l$ is the length of the dendritc and $B_{1}$ is as in Equation 5.

Statistics. Unless indicated otherwise, statistical analyses were made using the Mann-Whitney $U$ test (Krauth, 1983).

\section{Results}

Analyses were restricted to arbors of the type 1.2 ganglion cell identified previously by Hitchcock and Easter (1986). This cell type has a very large soma and 2-3 thick, slowly tapering primary dendrites that form a large dendritic field unistratified within the distal-most zone of the inner plexiform layer. The distinctive morphological features of this type of ganglion cell made identification unambiguous in both small and large retinas (see Materials and Methods).

We studied 6 dendritic arbors, each emanating from a single primary dendrite, from 6 different cells in 4 retinas ( 3 arbors from 2 small fish and 3 arbors from 2 large fish). The average standard body lengths and lens diameters of the fish were 2.0 $\mathrm{mm}$ and $4.2 \mathrm{~cm}$, and $3.7 \mathrm{~mm}$ and $14.4 \mathrm{~cm}$, respectively. In the small fish, arbors were selected from central retina that were "mature" in that they were no longer adding new dendrites (see Hitchcock and Easter, 1986). In the large fish, arbors were selcctcd from cclls in ccntral retina that would have been mature when at the same size and age as the arbors from the small fish. Because one cannot study dendritic growth concurrent with retinal stretch, we have adopted this strategy, and we have assumed that studying the arbors in small and large fish is analogous to studying the same cell at early and late points in time (see Discussion). Below, we refer to arbors from cells in small and large fish as small and large arbors, respectively.

\section{Morphometry}

Computer-generated drawings of the 6 arbors in flat-mount view are shown in Figure 1. The photomicrographs in Figure 2 illustrate the soma and proximal portion of the arbors illustrated in Figure 1, $A$ and $D$. The small dendritic arbors had a long axis of $400-550 \mu \mathrm{m}$, whereas the large arbors had a long axis of 600 $750 \mu \mathrm{m}$. A qualitative examination of the large and small arbors revealed that, except for a clear difference in their size, they shared several features in common. All arbors displayed relatively long main dendritic branches from which small segments were emitted. There was little overlap of dendritic branches, with only 1-2 intersections in a single arbor. As illustrated clearly in Figure 1, the primary dendrite of an arbor emanated from one side of the cell body, and for the most part, all subsequent branches remained on that side and projected radiately away from the soma. To determine how alike the architectures of small and large arbors were, quantitative measures of several morphometric parameters were compared, and the results are described below.

Several fundamental, numeric descriptors of dendritic architecture are listed in Table 1. These data indicate that, though 
A
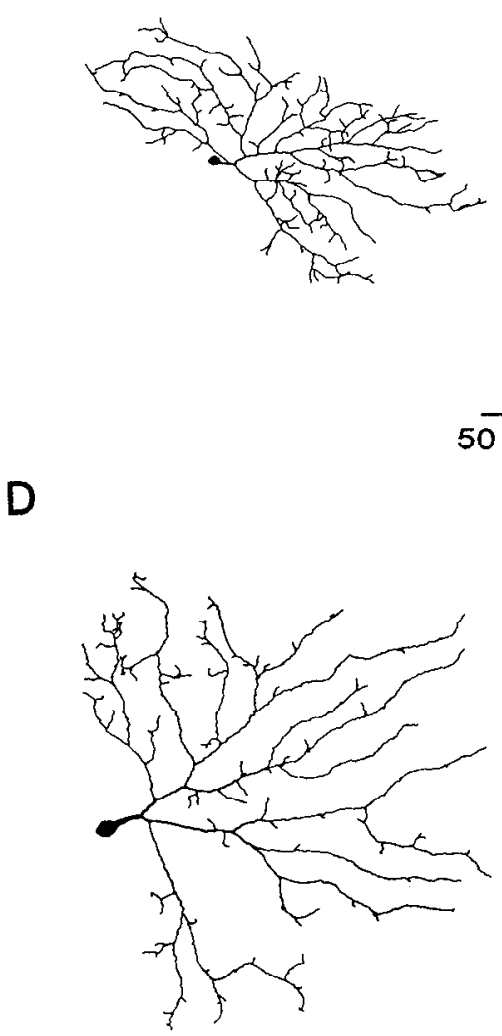

B

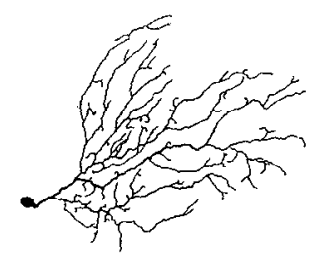

$E$

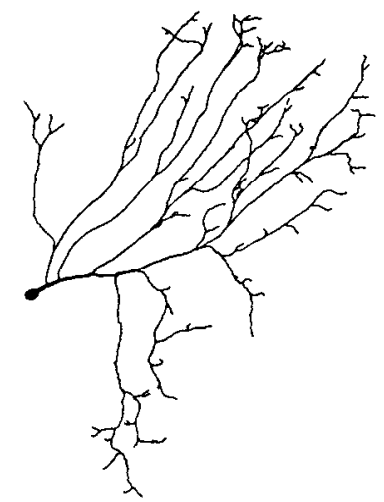

C
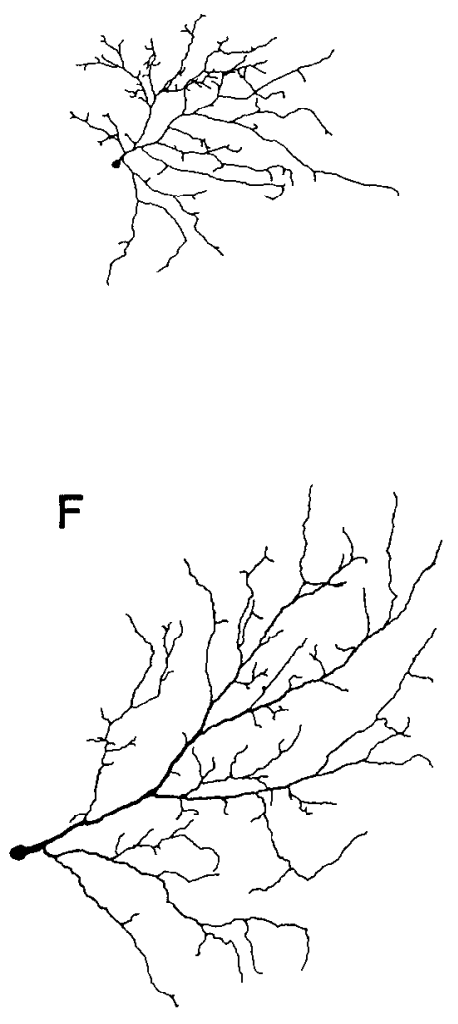

Figure 1. Computer-generated drawings of the 6 dendritic arbors studied. $A-C$, Arbors from type 1.2 ganglion cells of small/young fish. $D-F$, Arbors from type 1.2 ganglion cells of large/older fish.

the average total arbor length (sum of the lengths of all dendritic segments) of the small arbors was much less than that for the large arbors, the numbers of dendritic segments, branch points, and terminal endings and the maximum branch order were identical for the small and large arbors ( $p>0.1$ for all measures).

The reduction in the diameters of mother and daughter dendrites across branch points was also compared. A well-studied relationship between the size of mother and daughter dendrites is the "3/2-power rule" (Rall, 1962). The 3/2-power rule is a morphological constraint at branch points that must be followed in order to model a dendritic arbor as an equivalent cylinder; this modeling provides a relatively easy way to compute the electrotonic properties of a neuron (Rall, 1977). The rule states that, at a branch point, the diameter of the mother dendrite $(M)$ taken to the $3 / 2$ power equals the sum of the diameters of the daughter dendrites $\left(d_{1}\right.$ and $\left.d_{2}\right)$ each taken to the $3 / 2$ power. Measurements of the diameter of dendritic segments were made at 540 branch points ( 269 from small arbors and 271 from large arbors). For segments that displayed irregularities in caliber such as swellings and/or constrictions, an average diameter was calculated from measurements made every 3-7 $\mu \mathrm{m}$. Figure 3 illustrates these measurements for the branch point as a function of their branch order. Clearly, branch points in both small and large arbors adhered to the $3 / 2$-power rule very closely $(0.99 \pm$ 0.10 for small cells and $1.04 \pm 0.17$ for large cells). Further, the distributions of the ratios of branch diameters as a function of branch order were similar as well $(p>0.1)$.

The distributions of branch angles between daughter dendrites for the branch points in the 6 arbors were compared, and the results are illustrated in Figure 4 . Branch points in both small and large arbors showed the same range of $12-198^{\circ}$ (bin size, $16^{\circ}$ ). Moreover, the distributions for both small and large arbors were remarkably similar $(p>0.1)$, indicating a common feature to their branching architectures.

Finally, we examined the distribution of dendritic segment lengths as a function of branch order. The lengths of all dendritic segments within an arbor were first totaled, and then the percentage of this total contributed by segments of a given branch order was computed. As illustrated in Figure 5, the majority of segments were distributed between the 4th and 12th orders, and the distributions for both small and large arbors were identical $(p>0.1)$. These data indicate no redistribution of dendritic segment lengths within an arbor as it enlarges. Taken together, these morphometric data suggest that, as the retina grows by expansion, the dendritic arbors scale up spatially without any alterations in their geometry.

\section{Electrical modeling}

Formulations describing electrotonic properties of branching dendritic structures have shown that dendritic geometry, along with specific membrane $\left(R_{m}\right)$ and internal $\left(R_{i}\right)$ resistivity, plays a major role in determining a cell's passive cable properties. For example, if we model an arbor as an equivalent cylinder (arbors of type 1.2 ganglion cells may be so modeled because they follow the $3 / 2$-power rule), the total electronic length $(L)$ is proportional to the cylinder's geometry and $R_{m}$ as follows: 

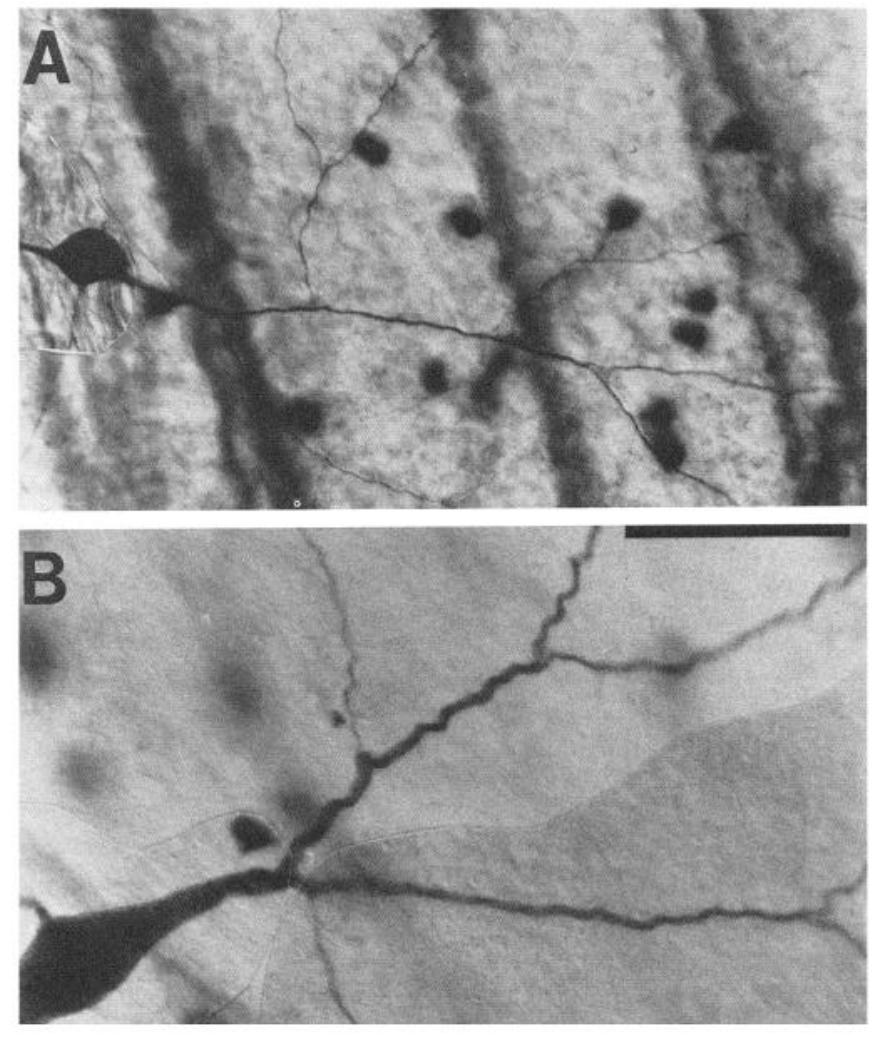

Figure 2. $A$ and $B$, Photomicrographs of proximal portion of dendritic arbors illustrated in Figure 1, $A$ and $D$, respectively. Scale bar, $40 \mu \mathrm{m}$ for $A$ and $B$.

$$
L \propto(l / \sqrt{d})\left(R_{m}\right)^{-1 / 2},
$$

where $l$ and $d$ represent the length and diameter of the equivalent cylinder (Jack et al., 1971; Gustafsson and Pinter, 1984). If we assume that 2 arbors are scaled versions of one another, as our morphometric data for small and large arbors indicate, then their equivalent cylinders will have similar geometry $(l / \sqrt{d})$ and thus, $L$ is simply inversely proportional to $R_{m}$. For our computations, we have assumed constant specific membrane and internal resistivity for all arbors (see Materials and Methods). Thus, if the arbors in this study are indeed scaled versions of one another, then they should have the same electrotonic lengths. We first computed the terminal electrotonic distances in each arbor by totaling the length constants (using Eq. 1) of all dendritic segments between a terminal ending and the soma. The total electrotonic length for each arbor was then computed as the average of all terminal electrotonic distances. Although terminal endings in large arbors were generally farther from the soma than those in small arbors $(387.2 \pm 151.1 \mu \mathrm{m}$ in large arbors, $244.9 \pm 83.2 \mu \mathrm{m}$ in small arbors), their average electrotonic distances (total electrotonic length of arbor) from the soma were the same $(0.86 \pm 0.39 \lambda$ for small arbors and 0.87 $\pm 0.33 \lambda$ for large arbors). These data indicate that the geometric term $(l / \sqrt{d})$ in Equation 7 remains constant for both small and large arbors, thus reinforcing our prior conclusion that the arbors of the type 1.2 ganglion cells we studied are scaled versions of one another.

As a more rigorous way of analyzing the electrotonic properties of these arbors, we calculated the steady-state voltage attenuation of a "synaptic" potential placed at a single terminal

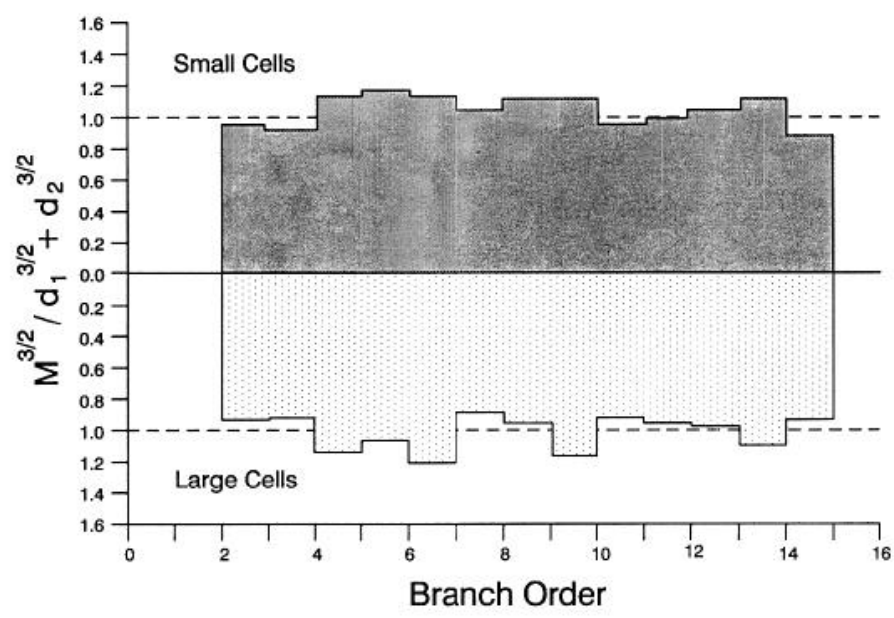

Figure 3. Histograms showing degree of adherence of branch points to the 3/2-power rule versus branch order. Data include measurements from all branch points (and adjoining dendritic segments) from the 6 arbors shown in Figure 1. The broken lines represent the ratio expected if the branch points followed the 3/2-power rule perfectly.

ending using formulations described by Rall (1959; see Materials and Methods). Figure 6 shows Sholl diagrams for the dendritic arbors illustrated in Figure 1, $A$ and $D$. Dendritic segments are drawn to the same anatomical scale, but relative thickness of segments is not represented. We mimicked the activation of a synaptic input by applying a voltage at various terminal endings and computing the voltage attenuation along the arbor at each branch point. In Figure 6 , a voltage of $100 \% V_{\max }$ has been placed at one dendritic ending (boxed value), and values of the voltage at other locations within the arbors are presented as percentages of $V_{\max }$. For both the small and the large arbor, the voltage is propagated effectively throughout the tree, with attenuation at the soma of only $40-45 \%$.

Similar computations were performed for voltage applications at all terminals in the 6 arbors, and a summary of our findings is presented in Figure 7. Each point represents the application of a voltage or synaptic potential at a terminal ending. The ordinate represents the percent of $V_{\max }$ that will be seen at the soma, and the abscissa shows the electrotonic distance of the terminal ending from the soma. The graph illustrates voltage application to 546 terminal endings ( 272 from small arbors and 274 from large arbors). Clearly, there is total overlap between

Table 1. Morphometric parameters of dendritic arbors

\begin{tabular}{lcc} 
& Small/young & Large/old \\
\hline $\begin{array}{l}\text { Total arbor length } \\
(\mu \mathrm{m})\end{array}$ & $4353.1 \pm 644.2$ & $6798 \pm 793.4$ \\
$\begin{array}{c}\text { Number of dendritic } \\
\text { segments }\end{array}$ & $181 \pm 14$ & $182 \pm 13$ \\
$\begin{array}{c}\text { Number of branch } \\
\text { points }\end{array}$ & $89 \pm 12$ & $90 \pm 13$ \\
$\begin{array}{c}\text { Number of terminal } \\
\text { endings } \\
\text { Maximum dendritic } \\
\text { branch order }\end{array}$ & $90 \pm 8$ & $91 \pm 10$ \\
\hline
\end{tabular}

Values are given as means \pm SD. 


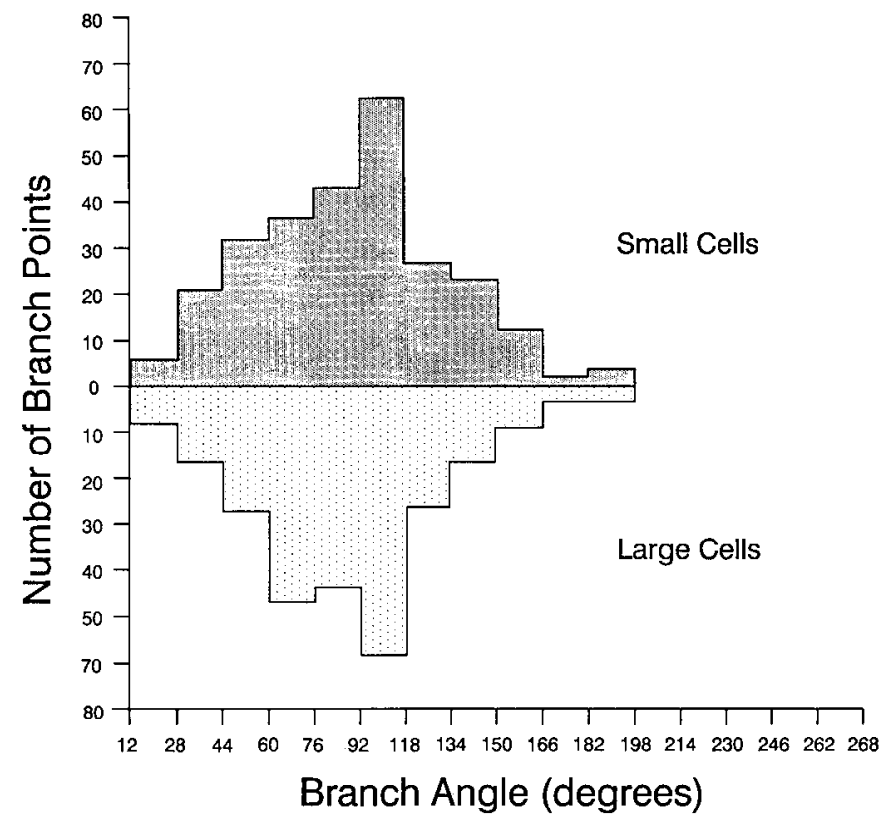

Figure 4. Histograms showings the distribution of branch angles between daughter dendrites. Each bin $\left(16^{\circ}\right)$ includes data from 3 dendritic arbors.

the distributions for small and large arbors ( $F$ test, $p>0.1)$, indicating that passive propagation of synaptic current is similar in both small and large cells.

\section{Discussion}

\section{Dendritic growth}

This study was undertaken to gain insights into the cellular changes that occur during brain growth and to test the hypothesis (Hitchcock and Easter, 1986) that the dendritic arbors of ganglion cells in the goldfish grow interstitially and uniformly with the expansion of the retina. The previous study concluded that the arbors of ganglion cells grow analogous to the manner in which a drawing would grow upon an inflating balloon. However, this conclusion was based upon limited anatomical data that did not include measures of dendritic segment length and diameter from individual cells. In the present study, we utilized numerous anatomical measures and electrotonic modeling to test further the "balloon-inflation" hypothesis.

Because dendritic growth concomitant with the retinal stretch could not be observed directly, we selected cells with mature arbors in large/old retinas and compared them to cells with mature arbors in small/young retinas. This is an indirect way of studying the development of those cells in the large/old fish and relies on our ability to infer their life history. Earlier studies have shown that (1) new ganglion cells are added to the retina from a ring of proliferative cells at the retinal margin (Johns, 1977), and (2) ganglion cells elaborate new dendrites within an annulus adjacent to this zone, whereas central to this annulus the arbors are mature (Hitchcock and Easter, 1986). Because of the appositional growth of the retina and the pattern of dendritic growth of the ganglion cells, we know that the large ganglion cells studied here, by virtue of their location within central retina, grew their arbors to maturity when the retina (and fish) were smaller and younger. The appearance of these large/old

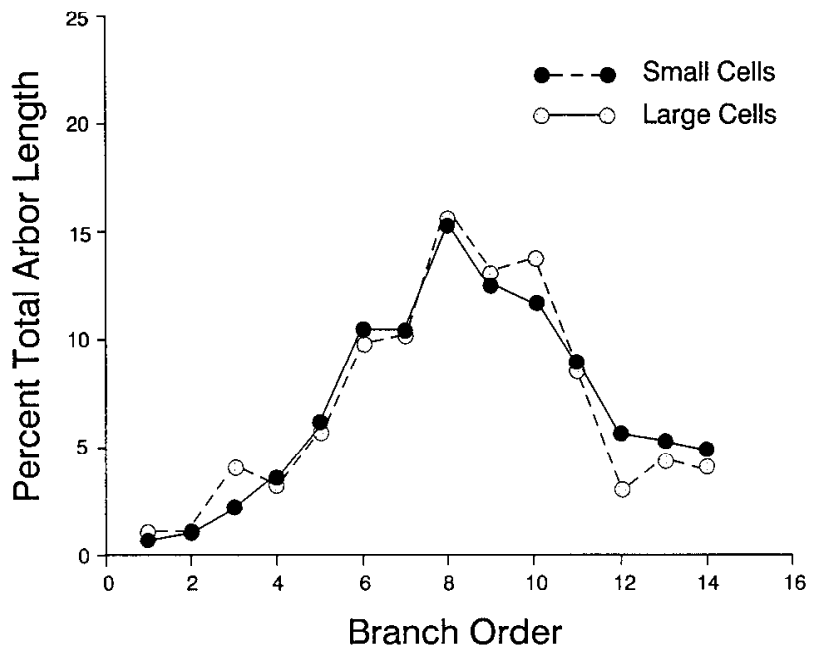

Figure 5. Scatter plot illustrating the relationship between the percentage of total arbor length and branch order. Each data point indicates the average value from 3 dendritic arbors, either small or large as indicated, shown in Figure 1.

arbors at an earlier point in their lives, therefore, is approximated by mature arbors in the retinas of small/young fish.

We used 2 quantitative approaches to compare the small and large arbors. First, we made comparisons of dendritic morphologies, and, second, we modeled the passive, steady-state spread of current within the arbors. The analysis of the passive cable properties provided an independent and complementary method for comparing dendritic geometry. Whereas the morphometric studies viewed each parameter individually, the electrical modcling reflected the interrclationships between parameters, for example, lengths, diameters, and location of dendritic segments within an arbor. Both sets of analyses, however, indicated that small and large arbors were virtually identical. This suggests that the dendritic arbors of ganglion cells scale up in size as the retina stretches, all the while preserving the architecture established during the phase of dendritic outgrowth (Hitchcock and Easter, 1986).

This exquisite preservation of dendritic architecture with retinal expansion is in contrast to that seen in mammals (Dann et al., 1988; Ramoa et al., 1988; Wong, 1990). For example, in the cat, the peripheral retina expands significantly during the first few postnatal weeks (Mastronarde et al., 1984). Although the dendritic arbors of ganglion cells residing there show a concomitant increase in length and girth, presumably in response to the expansion of the retina, they also undergo a significant rcmodcling during this time (Maslim et al., 1986; Dann et al., 1988; Ramoa et al., 1988). This remodeling results from an initially exuberant growth followed by the loss of superfluous processes (Dann et al., 1988; Ramoa et al., 1988); adult dendritic structure is achieved by about the end of the first postnatal month. This exuberant dendritic growth and subsequent remodeling is characteristic of many types of developing neurons (e.g., Purkinje cells; Sadler and Berry, 1984). The dendrites of ganglion cells in the goldfish achieve maturity without a transient, exuberant phase (Hitchcock and Easter, 1986), and our present results suggest that no apparent remodeling occurs as the arbors enlarge with retinal stretch. These differences may reflect the fact that the mammalian retina matures relatively quickly during a time when the functional requirements of the 

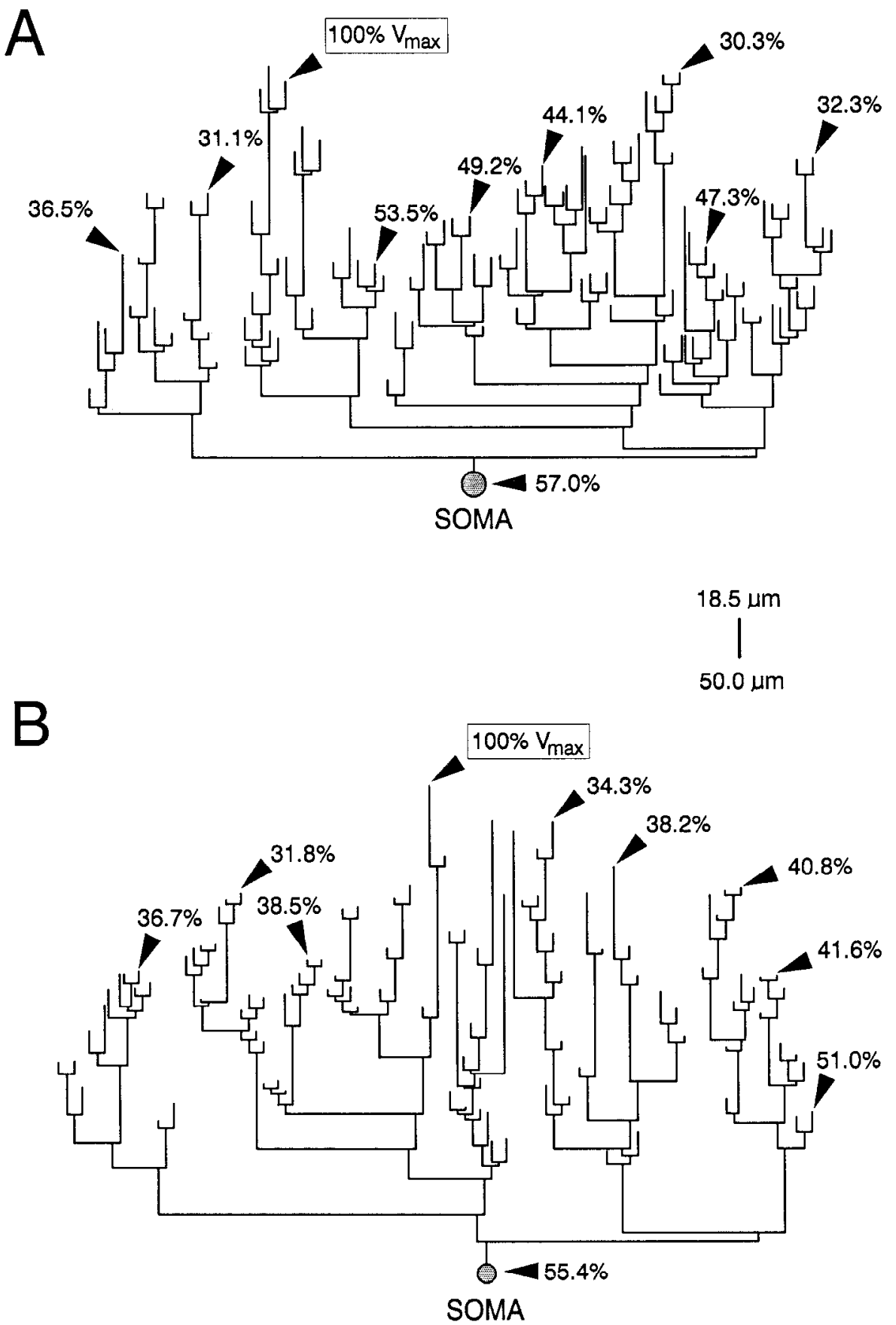

Figure 6. $A$ and $B$, Sholl diagrams representing the small and large arbors illustrated in Figure 1, $A$ and $D$ : cable modeling of attenuation of single voltage injection (i.e., the activation of a single synapse) within the arbors. The site of voltage injection is indicated by the boxed value of $100 \% V_{\max }$ (maximum voltage). Attenuation of this voltage at different dendritic terminals and soma is indicated by the arrowheads and is given as percent of $V_{\max }$. systcm are minimal, whercas in the fish, new ganglion cclls arc added to a preexisting retina that is mature and functional. In the fish retina, a continual remodeling of the dendritic architecture of mature cells would have the deleterious effect of continuously altering their integrative properties.

It is well documented that the dendritic growth of retinal neurons in fish is extremely protracted (Kock, 1982a; Kock and Stell, 1985; Hitchcock and Easter, 1986; Brown and Hitchcock, 1989). This neuronal enlargement requires a continual insertion of new plasma membrane, a net increase in the length and number of cytoskeletal elements, and, perhaps, the continual assembly and insertion of postsynaptic specializations (see below). The bulk of this molecular growth, however, is imposed upon a dendritic arbor whose architecture remains unchanged.
This indicates that, once a dendrite's architccturc is cstablishcd during the phase of active process outgrowth, it remains immutable and acts as a template upon which further growth is built. Although there is no experimental evidence for the mechanism underlying ganglion cell growth, it has been speculated that this results from mechanical forces produced by the expanding globe and retina (Hitchcock and Easter, 1986). The scaled growth of ganglion cells may thus be an epiphenomenon of the underlying balloon-like expansion of the retina.

\section{Electrical modeling}

In addition to providing a useful means of comparing the geometry of small and large arbors, the cable modeling also highlighted some of the functional consequences of the dendritic 
Figure 7. Attenuation at soma of single voltage injections, mimicking activation of a synaptic input, placed at different dendritic endings within the arbors as a function of the electrotonic distance of the input from the soma. Data points indicate voltage injections to all terminal endings in 3 small and 3 large arbors of this study.

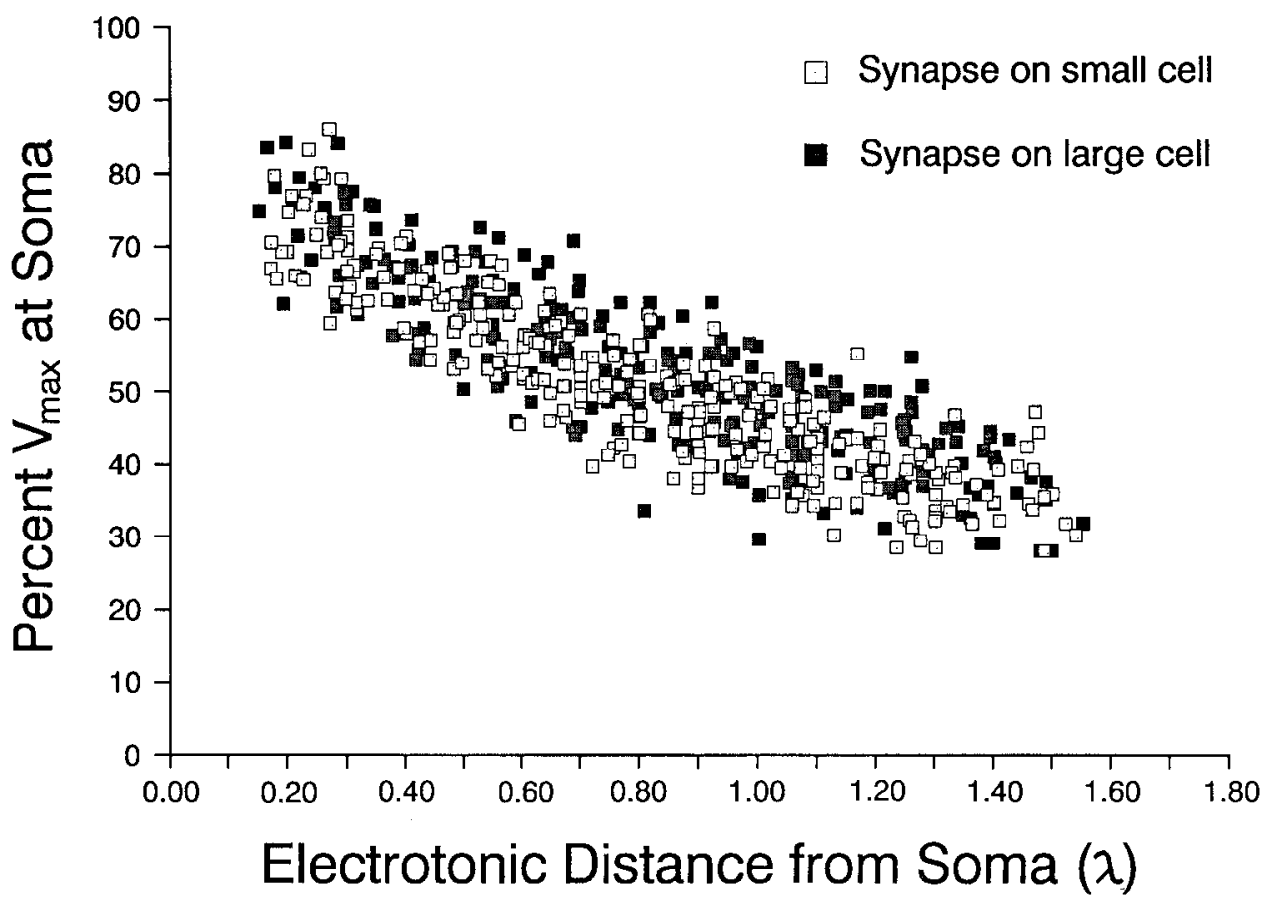

modeling suggests that these synapses, though moving farther away from the soma as the arbor enlarges, will remain at the same relative electrotonic distance from the soma. This suggests that the efficacy of synaptic inputs as a function of their position on the arbor will be conserved during cell growth. However, because of the increasing diameter of each dendritic segment over time, the input resistance of the arbor will progressively decrease. Thus, at each postsynaptic site, the same conductance change will produce a greater potential change in the small arbor than in the large one. As the arbor grows, therefore, more current must be generated by the activation of each afferent neuron to maintain a synaptic potential of constant amplitude. There are at least 2 ways in which this could be achieved: First, each postsynaptic site could, over time, generate increasingly greater synaptic currents, perhaps by increasing the number of channels present at that site or by changing the kinetics of individual channels. Second, a greater synaptic current could be generated by increasing the number of synapses from each afferent neuron that contact a given arbor. There is circumstantial evidence for this possibility. As the goldfish retina expands, there is a 4-5fold increase in the number of synapses within the inner plexiform layer when expressed on a per ganglion cell basis (Fisher and Easter, 1979). Therefore, the decreased input resistance could be compensated for by having each afferent neuron contact the arbor at an ever greater number of sites. If this developmental strategy is employed, the dendritic arbors of type 1.2 cells in large/old fish should receive more synaptic contacts than those in small/young fish.

\section{References}

Adams JC (1977) Technical considerations on the use of horseradish pcroxidasc as a ncuronal markcr. Neuroscience $2: 141-145$.

Bloomfield SA, Hitchcock PF (1989) Dendritic arbors of large field ganglion cells are scaled both morphologically and electrotonically during retinal expansion in the goldfish. Invest Ophthalmol Vis Sci [Suppl] 30:345.

Bloomfield SA, Hamos JE, Sherman SM (1987) Passive cable prop- it is reasonable to assume that preexisting synaptic inputs will remain at the same absolute sites on the arbor. The electrotonic

\section{Functional consequences}

Because of the uniformity of retinal expansion (Johns and Easter, 1977), as the dendrites of the type 1.2 ganglion cells enlarge,

\begin{abstract}
geometry and growth of type 1.2 cells. Although the large arbors
were some $60 \%$ longer than the small arbors, they all showed the same total electrotonic length of approximately $0.9 \lambda$. This
suggests that all arbors are electrically compact in that synaptic potentials generated in the most distal dendrites are presumably capable of influencing somatic and axonal responses. In addition, the arbors adhered closely to the 3/2-power rule at branch timize current flow in both directions across the branch (Bloomfield et al., 1987). As a result, not only can postsynaptic potentials (PSPs) move efficiently toward the soma, but currents generated proximally can invade the more distal dendritic of a single input), variability in resistivity values between and/ or within arbors, and active conductances. However, the passive able first approximations of the electrotonic behavior of these cells.
\end{abstract}


erties and morphological correlates of neurones in the lateral geniculate nucleus of the cat. J Physiol (Lond) 383:653-692.

Brown RN, Hitchcock PF (1989) Dendritic growth of DAPI-accumulating amacrine cells in the retina of the goldfish. Dev Brain Res 50:123-128.

Dann JF, Buhl EH, Peichl L (1988) Postnatal maturation of $\alpha$ and $\beta$ ganglion cells in cat retina. J Neurosci 8:1485-1499.

Easter SS Jr, Johns PR, Baumann LR (1977) Growth of the adult goldfish eye. I. Optics. Vision Res 17:467-477.

Fisher SK, Easter SS Jr (1979) Retinal synaptic arrays: continuing development in the adult goldfish. J Comp Neurol 185:373-379.

Gustafsson B, Pinter MJ (1984) Relations among passive electrical properties of lumbar $\alpha$-motoneurons of the cat. J Physiol (Lond) 356: $401-431$.

Hitchcock PF, Easter SS Jr (1986) Retinal ganglion cells in goldfish: a qualitative classification into four morphological types, and a quantitative study of the development of one of them. J Neurosci 6:10371050 .

Jack JJB, Miller S, Porter R, Redman SJ (1971) The time course of minimal excitatory post-synaptic potentials evoked in spinal motoneurons by group Ia afferent fibers. J Physiol (Lond) 215:353-380.

Johns PR (1977) Growth of the adult goldfish retina. III. Source of the new retinal cells. J Comp Neurol 176:343-358.

Johns PR, Easter SS Jr (1977) Growth of the adult goldfish eye. II. Increase in retinal cell number. J Comp Neurol 176:331-342.

Kock J-H (1982a) Neuronal addition and retinal expansion during growth of the crucian carp eye. J Comp Neurol 209:264-274.

Kock J-H (1982b) Dendritic tree structure and dendritic hypertrophy during growth of the crucian carp eye. J Comp Neurol 209:275-286.

Kock J-H, Reuter T (1978a) Retinal ganglion cells in the crucian carp (Carassius carassius). I. Size and number of somata in eyes of different sizes. J Comp Neurol 179:535-548.
Kock J-H, Reuter T (1978b) Retinal ganglion cells in the crucian carp (Carassius carassius). II. Overlap, shape, and tangential orientation of dendritic trees. J Comp Neurol 179:549-568.

Kock J-H, Stell W (1985) Formation of new rod photoreceptor synapses onto differentiated bipolar cells in the goldfish retina. Anat Rec 211:69-74.

Krauth J (1983) The interpretation of significance tests for independent and dependent samples. J Neurosci Meth 9:269-281.

Maslim J, Webster M, Stone J (1986) Stages in the structural differentiation of retinal ganglion cells. J Comp Neurol 254:382-402.

Mastronarde DN, Thibeault MA, Dubin M (1984) Non-uniform postnatal growth of the cat retina. J Comp Neurol 228:598-608.

Rall W (1959) Branching dendritic trees and motoneuron membrane resistivity. Exp Neurol 1:491-527.

Rall W (1962) Theory of physiological properties of dendrities. Ann NY Acad Sci 96:1071-1092.

Rall W (1977) Cable conductor theory and cable properties of neurons. In: Handbook of physiology, Sec 1, The nervous system, Vol 1, Cellular biology of neurons (Kandel ER, Geiger S, eds), pp 39-97. Bethesda, MD: American Physiological Society.

Ramoa AF, Campbell G, Schatz CJ (1988) Dendritic growth and remodeling of cat retinal ganglion cells during fetal and postnata development. J Neurosci 8:4239-4261.

Sadler M, Berry M (1984) Remodelling during development of the Purkinje cell dendritic tree in the mouse. Proc R Soc Lond [Biol] 221: 349-368.

Wong ROL (1990) Differential growth and remodelling of ganglion cell dendrites in the postnatal rabbit retina. J Comp Neurol 294:109132. 